\title{
When is a wave a wave? Long waves as empirical and theoretical constructs from a complex systems perspective
}

Citation for published version (APA):

Silverberg, G. P. (2005). When is a wave a wave? Long waves as empirical and theoretical constructs from a complex systems perspective. UNU-MERIT, Maastricht Economic and Social Research and Training Centre on Innovation and Technology. MERIT-Infonomics Research Memorandum Series No. 016 https://doi.org/10.26481/umamer.2005016

Document status and date:

Published: 01/01/2005

DOI:

10.26481/umamer.2005016

Document Version:

Publisher's PDF, also known as Version of record

Please check the document version of this publication:

- A submitted manuscript is the version of the article upon submission and before peer-review. There can be important differences between the submitted version and the official published version of record.

People interested in the research are advised to contact the author for the final version of the publication, or visit the DOI to the publisher's website.

- The final author version and the galley proof are versions of the publication after peer review.

- The final published version features the final layout of the paper including the volume, issue and page numbers.

Link to publication

\footnotetext{
General rights rights.

- You may freely distribute the URL identifying the publication in the public portal. please follow below link for the End User Agreement:

www.umlib.nl/taverne-license

Take down policy

If you believe that this document breaches copyright please contact us at:

repository@maastrichtuniversity.nl

providing details and we will investigate your claim.
}

Copyright and moral rights for the publications made accessible in the public portal are retained by the authors and/or other copyright owners and it is a condition of accessing publications that users recognise and abide by the legal requirements associated with these

- Users may download and print one copy of any publication from the public portal for the purpose of private study or research.

- You may not further distribute the material or use it for any profit-making activity or commercial gain

If the publication is distributed under the terms of Article $25 \mathrm{fa}$ of the Dutch Copyright Act, indicated by the "Taverne" license above, 


\section{MERIT-Infonomics Research Memorandum series}

When is a Wave a Wave? Long Waves as Empirical and Theoretical Constructs from a Complex Systems Perspective

\section{Gerald Silverberg}

2005-016

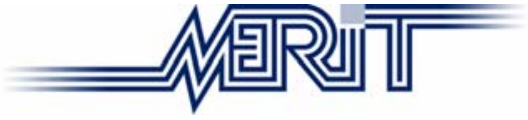

MERIT - Maastricht Economic Research Institute on Innovation and Technology

PO Box 616

6200 MD Maastricht

The Netherlands

T: +31433883875

$F:+31433884905$

http://www.merit.unimaas.nl

e-mail:secr-merit@merit.unimaas.nl

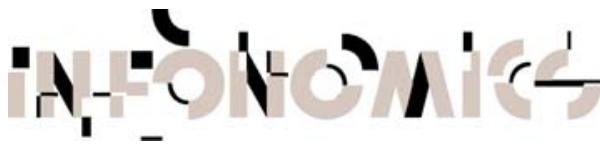

International Institute of Infonomics

c/o Maastricht University

PO Box 616

6200 MD Maastricht

The Netherlands

T: +31 433883875

F: +31 453884905

http://www.infonomics.nl

e-mail: secr@infonomics.nl 


\title{
When is a Wave a Wave? Long Waves as Empirical and Theoretical Constructs from a Complex Systems Perspective
}

\author{
Gerald SILVERBERG* \\ MERIT, Maastricht University
}

\begin{abstract}
While long waves have been seriously discussed by economists for almost one hundred years, to date there is no scientific consensus that particular frequency components are in any way privileged in the undoubtedly fluctuating history of modern economic and political development. This is disappointing for two reasons. First, the demonstration that robust, well-defined periodic components existed would present us with a plausible tool for forecasting. And second, they could (and their purported existence has variously been thought to) provide insight into underlying causal mechanisms that generate the observed patterns. The data, I argue, only provide support for a continuous spectral pattern of a power law, $1 / f^{\alpha}$ type. This is borne out in the paper by the analysis of political indicators such as the newly revised Modelski/Thompson sea power index and the Levy great powers conflict data. Claims for underlying low-dimensional chaos are only partly substantiated. Individual peaks at various frequencies in the spectrum are probably only due to "random noise" factors unique to segments of the record and not robust across countries and historical episodes. While one could then play the game of finding ad hoc explanations for why the 'K-wave' did not take its expected form in this or that century, from the perspective of the theory of complex dynamics it seems more plausible to conclude that a periodic model is not appropriate. Rather, the underlying model is more likely to be of the self-organized criticality or percolation type, characterized by power-law or fractal behavior rather than well-defined periodicity. I highlight some features common to several models of innovation/ economic dynamics and war/hegemonic cycles, such as highly clustered but nonperiodic critical events and resulting long life cycles of rise and decline, that may serve as a plausible explanatory mechanism for this 'revisionist' interpretation of the empirical record on long waves.
\end{abstract}

Keywords: long waves, war, hegemony, political cycles, complex systems, nonlinear dynamics

\section{Long Waves as an Exercise in Pattern Recognition}

Human beings seem to abhor a conceptual vacuum. They seem to be programmed by evolution to detect order in seeming chaos and recognize important configurations like previously encountered faces with uncanny accuracy. For indeed, the ability to exploit genuine order in the environment (the regularity of the seasons, the habits of prey) should impart a selective advantage to those who can properly conceptualize it. Perhaps this is the ultimate origin of the scientific enterprise. Yet this selfsame urge probably underlies such common behavioral anomalies as gamblers' delusions, superstition (religion?), technical trading and the like. Thus it behooves the scientific researcher to tread carefully in illdefined domains, and this for two reasons. First, so as not to fall victim to imagined patterns in the data, by carefully formulating null hypotheses of agnostic disorder against which a sound methodology is brought to bear, especially if the subject appeals to personal or community investments of faith and prospects of metaphysical redemption. And second, 
so as not to reject too neat patterns out of hand, or overlook yet other possibilities by becoming excessively fixated on ones that have historically dominated the literature.

There seem to be three primordial patterns that have dominated human thought for most of history. The first is stasis or apotheosis, a final state in which the universe and history will come to rest, preceded possibly by a period of monotonic convergence (the Final Judgment, Fukuyama's end of history, the Solow growth model). The second is cyclical (the seasons, the orbits of the planets, acoustical harmonies, the tides), consisting of simple or more complex combinations of periodic components, often in ratios of small integers. And third is what I would term the Heracleitan pattern, or lack of pattern: a universe that is never the same, that displays no law-like regularities and is intrinsically unpredictable. This corresponds perhaps to the vision of the German Historical School, Angus Maddison's phases of capitalist development, the efficient markets hypothesis, and the Box-Jenkins approach to time-series econometrics. God simply plays dice. From the perspective of modern statistical theory, this is of course also a pattern, one whose signature can also be detected with quantitative techniques. And as Beck [1] among others has pointed out, any stationary time series will be subdividable into periods of above and below average behavior, without this being due to any underlying 'mechanism' other than the persistence of random effects. Thus the Heracleitan vision may admit the differentiation of the historical record into eras or epochs, each due to unique historical factors, but not long waves in the sense they have been used in that literature: repetitions of a basic underlying mechanism allowing a certain predictability. The long-wave debate strikes me as still largely stuck within the conceptual confines of the second pattern (after conditioning perhaps on steady-state growth, an element of the first pattern). I will argue in the following that there may be an alternative situated somewhere in between the second and third possibilities that, while not being cyclical, has a distinctive pattern, and while showing elements of persistence, is not very predictable.

Why is pattern recognition important? Take one of the first documented instances of a 'scientific' identification of a pattern with major policy implications: the biblical Joseph's dream of seven years of plenty and seven years of famine. At first glance this is classical cyclical model that allows very accurate forecasting, probably the first aim of any pattern recognition enterprise. In fact, Hurst [2] convincingly showed that the Nile does not admit any such simple cyclical pattern. Instead, it displays remarkable persistence, with years of exceptionally high or low flow following each other much more frequently than pure chance would lead us to expect. This observation does not provide us with a forecasting tool like a truly cyclical model would, but does have important implications for the safe design of dams (and for the prudent stockpiling of grain). Thus other properties of a pattern such as persistence may differentiate it from pure chance without admitting much forecasting. Patterns are also important clues for the construction of models and the identification of underlying mechanisms. Thus Kepler's laws led to Newton's celestial mechanics, ${ }^{1}$ the fit of the east coast of South America into the west coast of Africa (a coincidence many had derided as illusory) ultimately lead to the theory of plate tectonics, and the complex spectra of gases led to the quantum mechanical theory of the atom. But neither the canals of Mars nor the patterns of bumps on people's heads led to the identification of alien civilizations or a phrenological theory of the human psyche. Thus purported patterns must be treated with care, and a methodologically sound case must be established that they really exist and are not figments of our order-loving fantasy.

To this end, this paper applies some of the ideas, models and methods used by myself and my collaborators in previous papers [3-7] that focused primarily on purely economic factors, to questions of long waves in war and international relations. For purposes of illustration and clarity of exposition I concentrate in the following empirical section on a dataset on seapower [8] and one on great power conflicts [9]. In the final 
theoretical section I attempt to integrate these results with existing models of technoeconomic evolution into an overarching theory of innovation and paradigm lifecycles.

\section{Long Waves in Warfare and Great Power Relations?}

While most long wave research has focused on economic variables, Kondratiev [10] already suggested that wars might be more likely to occur at the end of the upswing phases of his 50-60 year economic cycles, with causality running from economic competition for scarce resources and markets to the propensity for conflict. Goldstein [11] has made the relationship between armed conflict and economics the center of his research, with a greater emphasis on the autonomous dynamics of warfare than Kondratiev and a claim that the Levy data for great power conflict show 50 year cycles and correlates with his other indicators of long wave activity. Modelski and Thompson $[8,12]$ are particularly associated with a long wave theory of hegemonic seapower cycles of approximately 110 years in the period of European domination of the world (oceanic) economy since 1495 (subsequently extended to Sung China and the Eurasian overland economy from ca. 1000 AD onwards in [13]).

Beck [1] has convincingly argued that the question of long cycles can only be answered within the context of the well-understood methods of spectral analysis. ${ }^{2}$ I address this question for the Modelski/Thompson (MT) seapower data by computing the Herfindahl index of seapower concentration from their original data in place of their 'leading power' and 'systemic concentration' indices. ${ }^{3}$ Figure 1 plots the spectral density of this time series on a double-log scale. The spectral densities of the MT leading power indices are quite similar.

Two things are remarkable about this figure. First, there are no prominent individual frequencies standing out above the usual noisiness of spectral plots, in contrast to MT's claim for the existence of 110 cycles. ${ }^{4}$ Second, the spectral density is fitted quite well by a power-law function with slope -1.8325 over almost three decades of frequency.

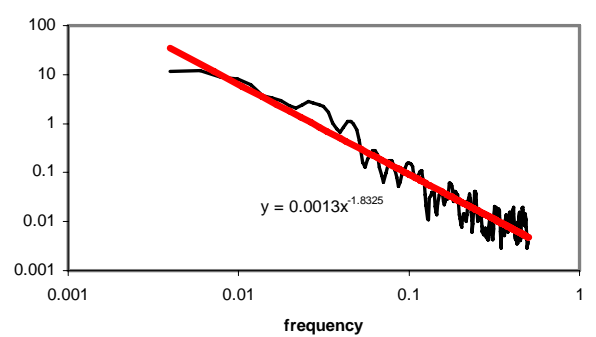

Figure 1 Spectral density of Herfindahl index of seapower concentration, on double-log scale, with fitted power law.

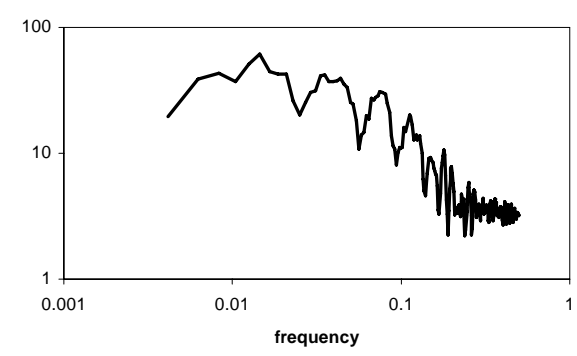

Figure 2 Spectral density of standardized residuals of Levy/Goldstein great war fatalities data, double-log scale.

Figure 2 plots the spectral density of the standardized residuals from fitting a negative binomial model to the Levy/Goldstein time series of fatalities in wars fought between great powers in the period 1495-1975. ${ }^{5}$ The estimated $\alpha$ of the negative binomial model is 10.7 and is significantly larger than zero at the $1 \%$ level on a likelihood ratio test, indicating that war fatalities are much more highly clustered than random. After conditioning on these facts, no distinct cyclical frequencies are apparent, in contrast to Goldstein's [11] conjecture of a 50-year cycle. However, something like a power-law pattern again seems to emerge, at least in the range 8-100 years. At shorter and longer time 
scales the spectrum resembles white noise. Quite similar results hold for the time series of all wars involving great powers in this period.

While at first sight these results may seem disappointing from a traditional longwave perspective, they accord rather well with what is also known about many economic time series since [18]: the spectral density seems to diverge at low frequencies and follow a power law. This is in contrast to the standard view of stationary time series characterized by short memory, where $\sum_{-\infty}^{+\infty}\left|c_{t}\right|<\infty$, with $c_{t}$ being the autocovariance of the series, implying a spectral density going to zero at low frequencies. Where this is not the case but the series is not integrated, long memory is present and correlations between distinct times persist longer than one would otherwise expect (recall the biblical case). Long memory can be characterized by a fractional differencing equation of the form $A(L)(1-L)^{d} x_{t}=B(L) \varepsilon_{t}$, where $L$ is the lag operator, $A($.$) and B($.$) are polynomials representing short-memory$ processes, and $-1<d<1$ is the long memory parameter. We can test the hypothesis that $d \neq 0$ by using Robinson's semi-parametric lpr estimator [6, 19]. For the seapower Herfindahl index this yields a value of $d$ of 0.89 , for the original MT LP series 0.88 , both significant at the $1 \%$ level. For the standardized residuals of the Goldstein/Levy great war fatalities dataset $d$ is 0.34 , again significant at the $1 \%$ level.

Richards [20] also claims to have found evidence for low-dimensional chaos in the original MT LP time series, after also dismissing claims for strict periodicity. She employs the Grassberger-Procacia correlation dimension to calculate a value around 3.5 using an embedding dimension of at least 7 (see her Fig. 3, p. 62). However, her diagram fails to show if any real convergence was obtained over a range of distances in the phase-space embedding, and, as she also points out, the number of observations (507) is probably insufficient to support this claim. She also fails to employ a Theiler window to exclude pairs of points within the linear autocorrelation time of each other, something that as become standard practice since her article was published (see e.g. [21, 22]). For this reason I have repeated her calculation using the $\mathrm{c} 2$ algorithm from the TISEAN package [22] using a Theiler window of 42 for the Herfindahl seapower time series.

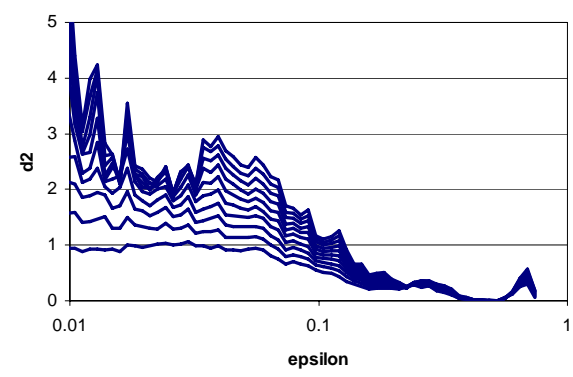

Figure 3 Correlation dimension of the Herfindahl index for embedding dimensions 19 as a function of neighborhood size.

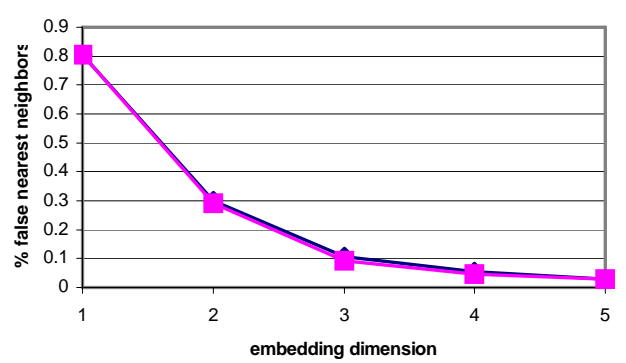

Figure 4 Share of false nearest neighbors as a function of embedding dimension, for Theiler window size 0 (triangles) and 42 (squares).

The theory of phase space embedding states that if a time series is produced by a low-dimensional chaotic system, then by creating vectors of dimension $m$ (the embedding dimension) using time-delay components of the original series, the topology of the strange attractor of fractional dimension $d$ will be reconstructed for sufficiently high $m$. Figure 3 shows the procedure for estimating the correlation dimension. Starting at embedding dimension 5 there is in fact a small range of convergence, but at a value of the correlation dimension just above 2 . That embedding dimension 5 is sufficient to recover the attractor is confirmed by Figure 4, which plots the percent of false nearest neighbors as a function of 
the embedding dimension for the Herfindahl index. This indeed falls off to almost zero at an embedding dimension of 5 for both zero and 42 year Theiler windows. No such convergence is apparent for the MT LP series (not shown), in contrast to the result reported by Richards. The percent of false nearest neighbors also rises from embedding dimension 4 to 5 in this case instead of falling off to zero.

A test has been proposed by Kennel and Isabelle [23] to differentiate between true low-dimensional chaos and colored or $1 / \mathrm{f}^{\alpha}$ noise, which can pass the above tests and also characterizes our datasets. It uses a one-step-ahead nonlinear predictor from the reconstructed trajectories in the phase-space embedding and compares the accuracy of forecasts with that of surrogate datasets generated randomly whose spectra resemble that of the original series. If low-dimensional chaos is present in the original series then the nonlinear forecaster should be statistically significantly more accurate in that case than for the surrogate data series. The results for the Herfindahl index are shown in Figure 5 (the test statistic is $\mathrm{N}(0,1)$ for the hypothesis that the original data does not allow higher nonlinear forecasting than surrogate data). ${ }^{6}$ Thus the ensemble of our time series tests indicate that the seapower Herfindahl index displays aspects of $1 / \mathrm{f}^{\alpha}$ noise, long memory, and low-dimensional chaos simultaneously, although the evidence for chaos, because of the shortness of the time series, is probably somewhat weak.

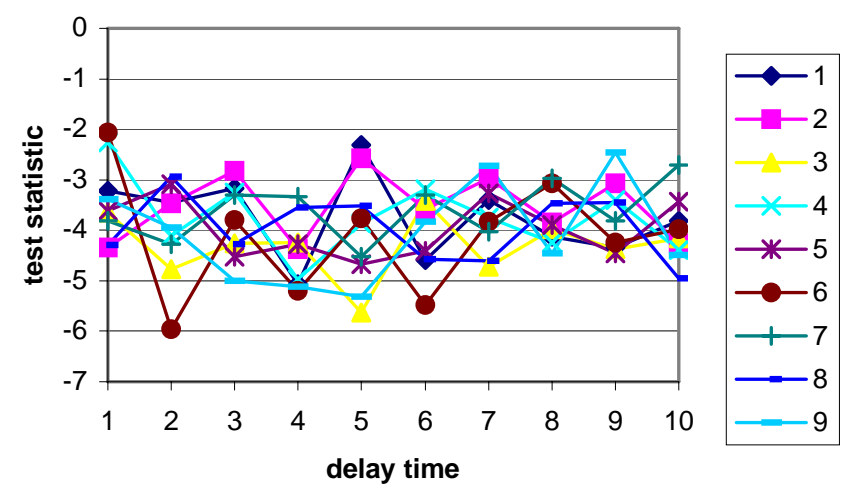

Figure 5 Nonlinear prediction statistic for the Herfindahl index of seapower for various embedding dimensions and time delays of the phase-space embedding.

To demonstrate how variable the division of the modern period into epochs of hegemonic dominance can be, Figure 6 shows which power had the largest actual high-seas fleet when the Herfindahl concentration index exceeded a given threshold, indicating (according to a variable criterion) sufficient concentration of seapower to justify using the word hegemon. ${ }^{7}$ For intermediate ranges of the Herfindahl index $(0.25-0.35)$ where the world seapower system fluctuates most of the time, the pattern begins to look more fractal than cleanly cyclical, with gaps indicating periods of transition or conflict between one dominant power and another. A threshold value between 0.25 and 0.3 probably best reflects the record of periods of dominance and conflict as commonly presented by naval historians.

\section{A Complex Systems Reformulation of the Long Wave Debate}

[1] and [24] present two extreme positions on the long wave question. The former (Beck) adheres to a hard-nosed statistical perspective that only highly regular and distinct individual periodicities revealed by spectral analysis count as true cycles. The latter (Goldstein) counters with two rather different and distinct concepts of a cycle. First, cycles 
in Goldstein's view need not be synchronized with calendar time. Taken to its extreme, this position would admit almost any stochastic process as cyclical, even though the 'periods' might be completely random and unpredictable. Unless the advocates of such a view can adduce a deterministic mapping from calendar time to their cyclical time, Beck's critique seems to me to be valid. Second, Goldstein maintains that if the underlying dynamic contains closed positive feedback loops, then we are also entitled to speak of cycles. This is both intriguing and prima facie wrong, since many such autocatalytic dynamical systems (starting with the simple Harrod-Domar model of economic growth) can produce very noncyclical behavior, such as steady-state exponential growth, chaos, or multistability. However, it does suggest that we need to extend our repertoire of dynamical systems and cyclical models to encompass more complex patterns.

threshold $=0.5$

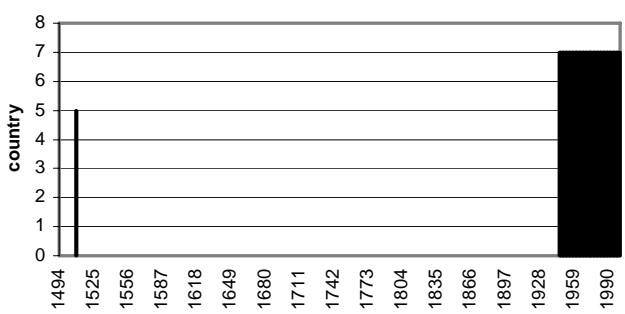

threshold $=0.35$

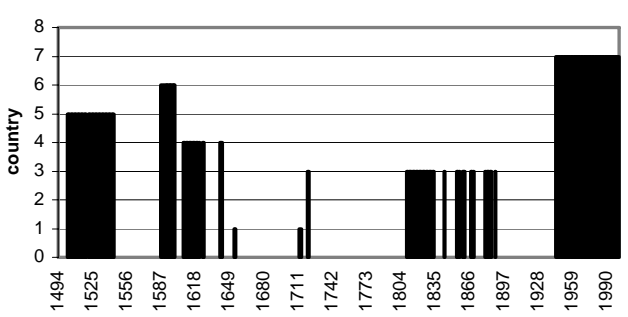

threshold $=0.25$

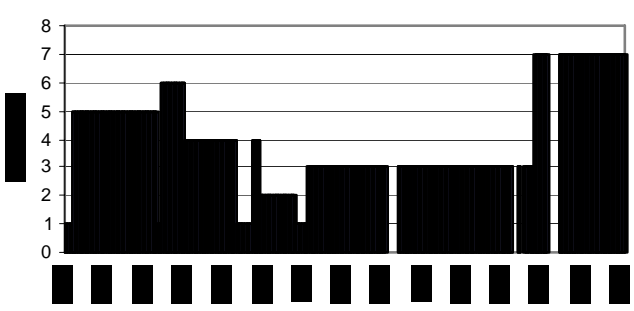

threshold $=0.4$

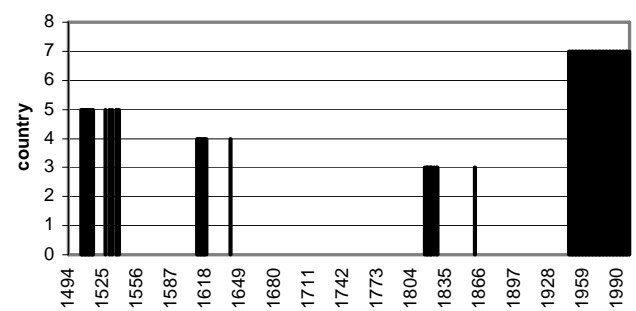

threshold $=0.3$

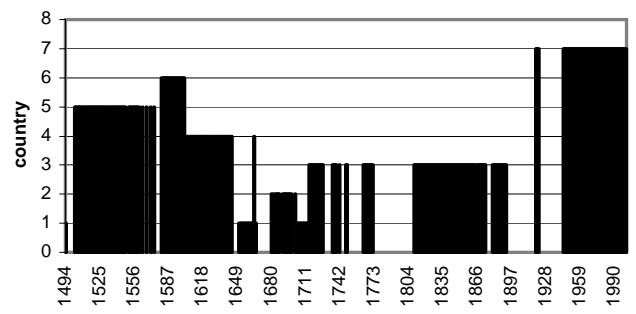

threshold $=0.2$

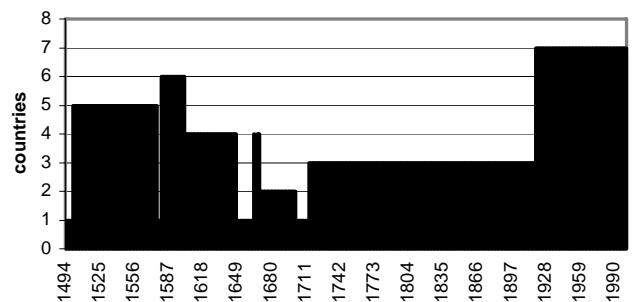

Figure 6 Variation in the dating of hegemonic epochs according to the $\mathrm{HI} \geq$ threshold criterion, using actual largest naval power in that year. The height of the bars codes for the hegemon as follows: 1=England $2=$ France $3=$ GB 4=NL 5=Portugal $6=$ =Spain $7=$ USA.

The illustrative analysis of war fatalities and alleged seapower cycles presented in this paper, as well as previous work on innovation cycles and economic growth, offers an alternative perspective. First, we need to differentiate between 'point-process-like' phenomena like wars and technical innovations on the one hand, and system-level macro variables like power relations and aggregate output on the other, both in terms of their roles in an overarching theory and in terms of the relevant statistical methods of analysis. The former are highly unpredictable and variable, but it seems that they can be characterized as 
following an underlying exponential growth path in the modern era, and simultaneously as more highly clustered than a simple Poisson process. After controlling for this randomness and clustering, there does not seem to be any evidence for cycles in either realm. This is not to say that they are completely autonomous random variables simply following a complex stochastic process and unaffected by the rest of society. However, there do seem to be many reasons to favor the view that they occupy a privileged position as driving rather than driven variables, except in some long-term sense that they respond probabilitistically to changes in the configuration of macro variables and institutional frameworks.

The analysis of macro variables such as the seapower indices and aggregate economic output also fails to detect distinct periodicities. This should not be regarded as a purely negative result, however, since a pattern does seem to emerge: one of power-law spectra. While in the economic realm this has been known since at least [18], it can be regarded either as a simple statistical nuisance to be eliminated by appropriate differencing of the time series, or as a source of insight into underlying mechanisms of a quite different kind than simple cycles. In the last few years complex systems theory has come to recognize such power law relationships as possible signatures of widespread universal mechanisms in nature and society $[25,35]$. Instead of reacting with disappointment that the classical cyclical view has not been confirmed, we should rather embrace this insight as a clue to the directions of fruitful future research.

These findings also shed some light on the shortcomings of previous research. If a variable is really characterized by a power law spectrum, then looking at a finite segment of data of length $T$ will always produce the largest spectral peak at period $T / 2$, the limit of our resolution. Thus it is not surprising that analysis of the 100-150 years of economic statistics available in the $20^{\text {th }}$ century has always led people to identify cycles of length 50-60 years, and that analysis of political data over the 500 years of the modern period even longer cycles. The existence of these continuous, as opposed to discrete, spectra, can also seduce researchers into chopping the frequency domain into all too regular pieces associated with e.g. period doubling characteristic frequencies such as the generation (30 years), the Kondratiev (60 years), the hegemonic (120 years), the democratization (250 years) and so forth, as [26] have argued. But it is precisely the scale-free (at least over a certain range of time scales) character of power-law spectra that sets them apart from other dynamical systems. Thus such classifications may be no more than convenient discretizations of the continuous hierarchy of time scales, unless very precise evidence is produced to the contrary. ${ }^{8}$ If we take them too literally we run the risk of falling victim to Whitehead's fallacy of misplaced concreteness.

The relationship between the 'event' level (innovations, wars) and the macro level deserves closer analysis, and is also subject to a number of methodological caveats. [27] finds clustering of innovations corresponding (with a lag) to his macro long-wave dating. [28] already argued that the causality ran from the macro level to innovations (depressions triggering the adoption of innovations). [11] finds a somewhat similar relationship between great power wars and subsequent inflation. [1], using a bispectral method, even finds evidence for this correlation even while rejecting long waves themselves. Thus crosscorrelations and causalities may very well be present between two variables, but this need not be evidence of long waves in either. [3] actually demonstrate in a model in which the causalities are clear (in this case running exclusively from innovations to macro behavior) that a long wave dating resulting from the macro variables does produce a strong correlation with fluctuations in innovation activity, and in such a way that both a 'productivity paradox' and a 'depression trigger' hypothesis seem substantiated. But in fact the macro variables simply amplify the stochastic variability of the innovation process with a delay - the innovation process itself displays no long waves whatsoever. And the implications of the correlation can easily be misinterpreted in either direction. The same 
may apply to the interrelationship between wars, economic fluctuations and power relations: causalities are difficult to tease out, and misleading conclusions may result from the superficial reading of correlations and timings.

Nevertheless, a certain consensus about the basic elements of a canonical 'long wave' model seems to be emerging. First, there is an underlying layer of events that initiate autocatalytic growth (or decay) processes, such as technological innovations, wars, changes of political regime, new institutional arrangements, and whatever initiates the rise of nations. These events occur randomly in time (but with exponential trend for the arrival rate in the modern period), are highly clustered, and are characterized by highly skewed and possibility power law size distributions (for innovations [29], for war [16]). Second, these events induce life cycles of some entity (a technology, an infrastructure, an institutional arrangement, nations) in competition with other entities in a Darwinian-like process of growth and decline, or diffusion and obsolescence. This process of structural change also has major implications at the aggregate, macro level, and may induce feedbacks back to the micro and even 'event' level. Examples can be found for technologies in [30,31] for war and international relations in [32,33]. These life cycles need not be of constant length or exactly repetitive pattern. In fact in $[3,4]$, both the speed of diffusion and the level of saturation have random characteristics. Nevertheless, the aggregation of this repetitive (but not periodic) pattern generates macro variables with distinctive power law properties. This seems to be a robust result even if we allow feedback from the macro to the innovation level and considerably greater micro diversity [34]. Whether we wish to classify this kind of system as displaying long waves is perhaps a matter of taste. In any event it transcends the Procrustean bed of the original long wave discourse and opens up a vaster richer domain of dynamical behaviors, some of which are probably more consistent with many long wave researchers' original intuitions (such as Schumpeter) than the primordial cyclical model ever was. It is also more consonant with the empirical 'stylized facts' that have begun to emerge from a more sophisticated statistical methodology in the last few years. Whether it will allow any sort of forecasting remains to be seen. The indicators of lowdimensional chaos for which I have found some rather tentative support might provide some ability to do short-term forecasting, although not in as straightforward a manner as the naïve cyclical model. However, I am very doubtful that we will ever be able to move very far from a firm knowledge of the pattern (in a statistical sense) to a firm ability to forecast. ${ }^{9}$ Thus we arrive at a view of history situated somewhere in between well-defined statistical laws governing the chance and necessity process of evolution, and the Heracleitan uniqueness of traditional historiographic narrative.

\section{Notes}

\footnotetext{
* I would like to thank George Modelski and William Thompson for making their recently updated leading power seapower dataset available to me, as well as Jack Levy for providing me with his war casualty dataset and a number of relevant papers. I would also like to thank Bart Verspagen for implementing the Poisson regression analysis of the Levy/Goldstein data and the nvc analysis of the Modelski/Thompson data.

${ }^{1}$ However, Kepler was led to them by the pursuit of his specious but mathematically appealing theory of the 'harmony of the spheres': that the orbits of the then known planets were determined by the spaces between the nested natural polyhedra. Only the recognition of irreducible discrepancies between the empirical data and this Platonic pattern recognition exercise forced Kepler to propose his conceptionally quite different laws, which in turn led to Newtonian mechanics. His search for celestial analogues for acoustic harmonies is also somewhat reminiscent of the nested oscillations of both Schumpeter's three-cycle theory and recent worldsystem models.

${ }^{2}$ I will return to the issue of whether alternative definitions of cycles make sense in the last section of this paper.

${ }^{3}$ MT define a 'leading power' (LP) index of seapower by first identifying the leading power over stretches of history between what they identify as critical hegemonic wars, and then calculating that power's share in the
} 
sum of the forces of all seapowers whose raw shares in total world seapower is greater than $10 \%$. This has the peculiar effect of imposing their long-wave dating on the index right from the start, since a) the leading power is not always the power with the largest naval forces in that year (this is true of Spain and Portugal vs. England and the Netherlands, in the $16^{\text {th }}$ and early $17^{\text {th }}$ centuries, and of England vs. the Netherlands and France for extended periods in the $17^{\text {th }}$ century, and of Great Britain vs. the USA between the First and Second World Wars) and b) their choice of decisive hegemonic wars can be criticized for arbitrariness (thus [14] pp. 157-8 points out that MT leave out the Thirty Years' War (1619-48/59), the War of Austrian Succession (1739-1748), and the Seven Years' War (1755-1763), which most analysts include in any discussion of great power hegemony both for their global extent and intensity of casualties, not to mention lesser conflicts such as the wars between Charles V and France (1521-1559) and the Dutch War of Louis XIV (1672-1678), which played significant roles in establishing the European hegemon). In part this is a result of MT's exclusive emphasis on global oceanic seapower to the complete neglect of land and regional naval forces (thus promoting Portugal to hegemonic status in the $16^{\text {th }}$ century, although most analysts do not even consider it a great power at any time in the entire period, and excluding the Ottoman Empire). And it may also reflect an unconscious bias on MT's part in favor of their 110 year long-wave (pre)conception.

MT's other, 'systemic concentration' (SC) index is based on a formula proposed by [15]):

$$
S C=\sqrt{\left(\sum s_{i}{ }^{2}-1 / N\right) /(1-1 / N)},
$$

where $s_{i}$ is the share of power $i$ in the total population of $N$ powers. There are a number of inconsistencies in the way this index is calculated in Appendix B of [8]). First, the shares do not always sum to one (sometimes deviating by as much as $10 \%$ ). Second, the number of great powers $N$ entering the formula does not always correspond to the number of countries with nonzero shares (e.g., when a great power drops out of the population it sometimes, but not always, continues to be counted in the value of $N$ ). This is especially problematic since the Ray and Singer formula will undergo nontrivial jumps as $N$ changes even if the sum $\Sigma s_{i}{ }^{2}$ (which is in fact the usual Herfindahl index of concentration widely used in industrial economics) is otherwise practically unchanged. Finally, a number of values of MT's SC index seem to be simply miscalculated for reasons that are not apparent. A detailed analysis of the problems of the MT indices can be obtained from the author as an Excel spreadsheet.

To correct for these problems I have recalculated a systemic concentration index by

1) renormalizing the shares taken from MT's Tables 5.6-5.9 by dividing them by the sum of shares in that year, thereby forcing them to sum to one. This is only a quick and dirty solution. A better one would be to recalculate the shares from MT's raw data, but I have not found the time to do so until now;

2) using the straight Herfindahl index $\Sigma s_{i}^{2}$ instead of the Ray and Singer index. This is not sensitive to the proper specification of $N$ and the inclusion or exclusion of marginal powers (and thus would also allow seapowers under MT's $10 \%$ threshold to be included in the calculation without significantly changing the result, something I have also not yet undertaken in the present analysis).

In the following I will rely primarily on this Herfindahl SC index, since it is not affected by ambiguities in the identification of the leading power or the number of powers, the two problems impairing the usefulness of MT's LP and SC indices. For purposes of comparison I have also calculated a consistent SC index based on the Ray and Singer formula (which is much more variable than the one in MT's Appendix B) and an alternative LP index, MaxS, reflecting the share of the naval power whose forces were actually largest in any given year. This analysis of the problems and inconsistencies of MT's LP and SC indices is not meant to detract from their immense contribution to putting the discussion of hegemonic cycles on a firm empirical and theoretical foundation. It is an unavoidable correlate of quantitative analysis that the devil is always in the details.

${ }^{4}$ Plotting on a logarithmic scale gives a better indication of the relative significance of individual peaks in the spectrum than on a linear scale. See [1], Appendix, for a discussion of how to calculate the significance levels of spectral densities.

${ }^{5}$ This data is taken from [11] Appendix B, variable GPWAR of War Indicators table, which in turn is based on [9]. Goldstein distributes the fatalities evenly over the years of a war, except for the first and last year, which are apportioned half as many. In contrast to [1], I do not perform a spectral analysis directly on this data, since they obviously have characteristics rather different from usual random variables, in particular the large number of years with zero values. Instead I regard them as count data in the tradition of war analysis in [9,16,17]. The null hypothesis is that of a Poisson process with log-linear time trend. The alternative hypothesis is that of a negative binomial model representing a more clustering process than pure Poisson with a parameter $\alpha$ reflecting the degree of random clustering. I also introduce a dummy variable $\mathrm{x}_{1815}(=0$ before 1815, 1 afterwards) to reflect the often remarked structural change in the data after 1815: great power wars become less frequent but more severe. The method of Poisson regression is then applied to each model (see [5] for details) for the Poisson arrival rate $\lambda$ :

$$
\ln \lambda(t)=a_{1}+a_{2} x_{1815}+b_{1} t+b_{2} x_{1815} t
$$


The estimated point variances are $\lambda(t)$ for the Poisson model and $\lambda(t)(1+\alpha \lambda(t))$ for the negative binomial one. The standardized residuals are then $(x(t)-\lambda(t)) / \sqrt{\lambda(t)(1+\alpha \lambda(t))}$, where $x(t)$ are the annual observations. This controls for the exponential trend and the heteroskedasticity of the data according to the relevant model. Spectral analysis is then applied to these residuals. The net result is not remarkably different than that obtained by [1], however.

${ }^{6}$ The 507 observations of the original series are extended by three repetitions of the first value and two of the last to obtain the power of two observations (512) needed by the nvc algorithm. Analysis of 256 'unadulterated' observations from the beginning, middle and end of the original series showed similar results, with the beginning and middle being perhaps somewhat less significant and the end distinctly more so.

${ }^{7}$ Recall that the MT LP index reports the share of the power MT identify as the leading power in that time interval even if that power does not currently possess the largest fleet by MT's own measures. MT define hegemony to apply when the LP index exceeds $50 \%$, but of course their results could also be examined as a function of a variable threshold.

${ }^{8}$ [26] also propose a power law for their nested cascade of world system processes. Quite apart from the plausibility of their identification of specific periodic processes in the very uncertain empirical record encompassing 8000 years of human history (and even in the case of the seapower dataset it should now be clear that the claim for periodicity is highly dubious), it is evident that regressing the number of repetitions $n_{p}$ of a periodic process in a time interval of length $T$ against the period $p$ of the process $\left(n_{p}=T / p\right)$ will always yield a power-law exponent of -1 . Thus it is not surprising that they obtain an exponent of -0.9991 : they are simply estimating a mathematical/conceptual identity and not a relationship between independent observations.

${ }^{9}$ In this the social system may be analogous to the study of earthquakes, where the well-established Gutenberg-Richter (power) law and some knowledge about the temporal clustering properties of earthquakes still does not provide us with any lever for forecasting.

\section{References}

[1] Beck, N., 1991, "The Illusion of Cycles in International Relations", International Studies Quarterly, 35: $455-476$.

[2] Hurst, H., 1951, "Long Term Storage Capacity of Reservoirs", Transactions of the American Society of Civil Engineers, 116: 770-799.

[3] Silverberg, G. and Lehnert, D., 1993, "Long Waves and 'Evolutionary Chaos' in a Simple Schumpeterian Model of Embodied Technical Change", Structural Change and Economic Dynamics, 4: 9-37.

[4] Silverberg, G. and Lehnert, D., 1996, "Evolutionary Chaos: Growth Fluctuations in a Schumpeterian Model of Creative Destruction", in Barnett, W., Kirman, A. and Salmon, M., (eds), Nonlinear Dynamics in Economics, Cambridge: Cambridge University Press.

[5] Silverberg, G. and Verspagen, B., 2003, "Breaking the Waves: A Poisson Regression Approach to Schumpeterian Clustering of Basic Innovations", Cambridge Journal of Economics, 27: 671-693.

[6] Silverberg, G. and Verspagen, B., 2003, "Long Memory in the World Economy since the 19th Century", in Rangarajan, G. and Ding, M., (eds), Long Memory and its Applications, Berlin: Springer.

[7] Silverberg, G., 2003, "Long Waves: Conceptual, Empirical and Modelling Issues", Maastricht: MERIT Research Memorandum RM2003-15, http://www.merit.unimaas.nl/publications/rmpdf/2003/rm2003015.pdf, forthcoming in Hanusch, $\mathrm{H}$. and Pyka, A. (editors), The Elgar Companion to Neoschumpeterian Economics, Aldershot: Edward Elgar.

[8] Modelski, G. and Thompson, W.R., 1988, Seapower in Global Politics, 1494-1993, London: Macmillan.

[9] Levy, J. S., 1983, War in the Modern Great Power System, 1495-1975, Lexington: University Press of Kentucky.

[10] Kondratieff, N. D., 1925/1979, "The Long Waves in Economic Life", Review, 2: 519-562.

[11] Goldstein, J.S., 1988, Long Cycles. Prosperity and War in the Modern Age, New Haven and London: Yale University Press.

[12] Modelski, G., 1987, Long Cycles in World Politics, London: Macmillan.

[13] Modelski, G. and Thompson, W.R., 1996, Leading Sectors and World Powers, Columbia, SC: University of South Carolina Press.

[14] Levy, J.S., 1991, "Long Cycles, Hegemonic Transitions, and the Long Peace", in Kegley, C. W. Jr., (ed.), The Long Postwar Peace, New York: HarperCollins.

[15] Ray, J.L. and Singer, J. D., 1973, "Measuring the Concentration of Power in the International System", 
Sociological Methods and Research, 1: 403-437.

[16] Richardson, L.F., 1960, Statistics of Deadly Quarrels, Chicago: Quadrangle.

[17] Levy, J.S. and Morgan, T. C., 1986, "The War-Weariness Hypothesis: An Empirical Test", American Journal of Political Science, 30(1): 26-49.

[18] Granger, C. W. J., 1966, "The Typical Spectral Shape of an Economic Variable", Econometrica, 34(1): $150-161$

[19] Robinson, P., 1995, "Log-periodogram of time series with long range dependence", Annals of Statistics, 23: $1048-1072$.

[20] Richards, D., 1993, "A Chaotic Model of Power Concentration in the International System", International Studies Quarterly, 37: 55-72.

[21] Abarbanel, H.D. I., 1996, Analysis of Observed Chaotic Data, Berlin: Springer.

[22] Hegger, R., Kantz, H. and Schreiber, T., 1999, "Practical implementation of nonlinear time series methods: The TISEAN package", Chaos, 9: 413-435.

[23] Kennel, M.B. and Isabelle, S., 1992, "A Method to Distinguish Possible Chaos From Colored Noise and Determine Embedding Parameters", Physical Review A, 46(6): 3111-3118.

[24] Goldstein, J.S., 1991, "The Possibility of Cycles in International Relations", International Studies Quarterly, 35: 477-480.

[25] Bak, P., 1996, How Nature Works: The Science of Self-Organized Criticality, New York: Springer.

[26] Devezas, T. and Modelski, G., 2003, "Power Law Behavior and World System Evolution: A Millennial Learning Process", Technological Forecasting \& Social Change, 70: 819-859.

[27] Kleinknecht, A., 1990, "Are there Schumpeterian Waves of Innovations?", Cambridge Journal of Economics, 14: 81-92.

[28] Mensch, G.O., 1975, Das technologische Patt, Frankfurt: Umschau.

[29] Silverberg, G. and Verspagen, B., 2004, "The size distribution of innovations revisited: an application of extreme value statistics to citation and returns measures of patent significance", forthcoming in Journal of Econometrics, also Maastricht: MERIT Research Memorandum 2004-021, http://www.merit.unimaas.nl/publications/rmpdf/2004/rm2004-021.pdf.

[30] Grübler, A., 1990, The Rise and Decline of Infrastructures. Dynamics of Evolution and Technological Change in Transport, Heidelberg: Physica-Verlag.

[31] Grübler, A. 1998, Technology and Global Change, Cambridge: Cambridge University Press.

[32] Doran, C.F. and Parsons, W., 1980, "War and the Cycle of Relative Power", American Political Science Review, 74: 947-965.

[33] Doran, C.F., 2003, "Economics, Philosophy of History, and the "Single Dynamic" of Power Cycle Theory: Expectations, Competition, and Statecraft", International Political Science Review, 24(1): 1349.

[34] Silverberg, G. and Verspagen, B., 1996, "From the Artificial to the Endogenous: Modelling Evolutionary Adaptation and Economic Growth", in Helmstädter, E. and Perlman, M., (eds), Behavorial Norms, Technological Progress and Economic Dynamics: Studies in Schumpeterian Economics, Ann Arbor, MI: University of Michigan Press.

[35] Sornette, D. 2000, Critical Phenomena in Natural Sciences. Chaos, Fractals, Selforganization, and Disorder: Concepts and Tools, Berlin: Springer. 